\title{
Clinical Implications of S100A12 and Resolvin D1 Serum Levels, and Related Genes in Children with Familial Mediterranean Fever
}

\author{
Zeinab Y. Abdallah ${ }^{1}$ Mona Ibrahim ${ }^{1}$ Manal M. Thomas ${ }^{20}$ Hisham Megahed $^{2}$ Ghada Nour Eldeen ${ }^{3}$ \\ Khaled Hamed ${ }^{2}$ Mohamed Fares ${ }^{4,5}$ Mahmoud ElHefnawi ${ }^{4}$ Hala T. El-Bassyouni²
}

\footnotetext{
${ }^{1}$ Division of Human Genetics and Genome Research, Department of Biochemical Genetics, National Research Centre, Cairo, Egypt

${ }^{2}$ Division of Human Genetics and Genome Research, Department of Clinical Genetics, National Research Centre, Cairo, Egypt

${ }^{3}$ Division of Human Genetics and Genome Research, Department of Molecular Genetics and Enzymology, National Research Centre, Cairo, Egypt

${ }^{4}$ Division of Engineering Research, Department of Informatics and Systems, Biomedical Informatics and Chemoinformatics Group, National Research Centre, Cairo, Egypt

${ }^{5}$ Division of The Veterinary Medicine, National Research Centre, Cairo, Egypt
}

J Child Sci 2021;11:e163-e169.

\author{
Address for correspondence Zeinab Y. Abdallah, PhD, Division of \\ Human Genetics and Genome Research, Department of Biochemical \\ Genetics, National Research Centre, Cairo 12622, Egypt \\ (e-mail: zeinabwakad@yahoo.com).
}

\author{
Abstract \\ Keywords \\ - familial \\ Mediterranean fever \\ - inflammation \\ - MEFV gene \\ - S100A12 protein \\ - resolvin D1
}

The aim of this article was to study the role of S100A12 and resolvin D1-related genes and serum levels in the diagnosis and detection of subclinical inflammation in children with familial Mediterranean fever (FMF) during the quiescent stage of the disease. Seventy-eight children with FMF during the silent state and 60 healthy control were studied. Serum S100A12 and resolvin D1 were quantitatively measured using enzymelinked immunosorbent assay. In addition, the levels of C-reactive protein, erythrocyte sedimentation rate, and hemoglobin were determined. The clinical severity was evaluated. The link between the Mediterranean fever (MEFV) gene and the genes related to the two studied biomarkers was also assessed. Correlation between S100A12 and resolvin D1 and the clinical severity was assessed. The mean serum levels of S100A12 and resolvin D1 were 847.4 and 793.3, respectively, which were highly significantly increased $(p=0.001)$ compared with the controls (324.3 and 235.1, respectively). The receiver operating characteristic curve test showed that S100A12 had a sensitivity of $97.4 \%$ and specificity of $80 \%$ with cutoff value of 529.5 , while resolvin D1 showed a sensitivity of $100 \%$ and specificity of $50 \%$ with cutoff value of 231.2. A correlation was detected between the clinical severity and S100A12 and resolvin D1. This study delineated that $\mathrm{S} 100 \mathrm{~A} 12$ and resolvin D1 are sensitive biomarkers to detect the degree of inflammation in children with FMF during the silent period. Consequently, we recommend adjusting the colchicine dose to ameliorate the disease's symptoms and to improve the quality of life in these patients. received

February 6, 2021

accepted after revision

April 18, 2021
DOI https://doi.org/

10.1055/s-0041-1731303.

ISSN 2474-5871. (c) 2021. The Author(s).

This is an open access article published by Thieme under the terms of the Creative Commons Attribution License, permitting unrestricted use, distribution, and reproduction so long as the original work is properly cited. (https://creativecommons.org/licenses/by/4.0/)

Georg Thieme Verlag KG, Rüdigerstraße 14, 70469 Stuttgart, Germany 


\section{Introduction}

Familial Mediterranean fever (FMF) is the most common monogenic autoinflammatory disease in the world; its prevalence is very high among people from the eastern Mediterranean such as Jews, Turks, Armenians, and Arabs. ${ }^{1}$ Although it is known to be inherited autosomal recessively, a substantial number of heterozygotes are presently expressing the phenotypic characteristics. ${ }^{2}$ The disease is characterized by recurrent fever episodes, which may be accompanied by serositis, arthritis, vasculitis, dermal manifestations, and long-term complications, mainly renal. ${ }^{3}$ The episodes are self-limiting lasting 12 to 72 hours, and the interval between the episodes is extremely variable from weeks to years. ${ }^{4}$ The most common genetic mutations encoded from exon ten and exon 2 are responsible for more than $85 \%$ of FMF cases in the Mediterranean basin. ${ }^{5}$ The Mediterranean fever (MEFV) gene encodes for protein pyrin (marenostrin), mostly in neutrophils and macrophages and has a crucial role in apoptosis and inflammatory pathways. M694V is the most common mutation in Turk, Armenian, and Jewish populations, while M694I is mostly seen in the Arabic population. ${ }^{6}$

There has been an increasing interest in the function of S100A12 protein and its role as an indicator of inflammation. S100A12 was shown to be associated with active FMF. It is involved in the pathogenesis of this disease, and its release is independently regulated from inflammasome activation. ${ }^{7}$ It shows an excellent relation to disease activity, and serum levels are higher in patients with unstable disease state under colchicine treatment. ${ }^{8}$

Bioactive derivatives of omega-3 fatty acids, mainly eicosapentaenoic acid and docosahexaenoic acid, are essential for the innate immune system and have natural anti-inflammatory, pro-resolving properties. ${ }^{9}$ Resolvin mainly switches inflammation to the resolution phase by inhibition of endothelial migration and infiltration of leukocytes and promotion of clearance of apoptotic polymorphonuclear leukocytes. The efficacy of endogenous resolvin D1 has been tested for antiinflammatory actions in several in vivo experimental models. ${ }^{10}$ The serum levels of resolvin D1 increase in both the attack and silent periods of FMF and correlate with classical biomarkers of inflammation such as highly sensitive $\mathrm{C}$-reactive protein (CRP) and serum amyloid A (SAA). ${ }^{11}$

Colchicine is the mainstay of FMF treatment and should be started once a clinical diagnosis is established. Its regular use prevents attacks and suppresses chronic subclinical inflammation. Anti-interleukin-1 drugs emerged as promising treatment options in patients who fail to respond or tolerate colchicines. ${ }^{12,13}$ This work aimed to study the role of S100A12 and resolvin D1 in the diagnosis and detection of subclinical inflammation in children with FMF during the quiescent stage of the disease.

\section{Patients and Methods}

Seventy-eight Egyptian FMF children during the quiescent disease state and 60 age and sex-matched healthy controls were enrolled in this study. The diagnosis of FMF was established according to the Tel-Hashomer criteria. ${ }^{14} \mathrm{~A}$ quiescent disease state was considered with clearance of all the signs and symptoms of an FMF attack for at least two consequent weeks. All the patients were on colchicine treatment when the samples were drawn.

The FMF patients were recruited from the Clinical Genetics Department outpatient clinic at the Medical Center of Excellence, National Research Centre. The participants did not have other systemic diseases (diabetes mellitus, chronic renal failure, malignancy and ischemic heart disease) or performed heavy exercises. Other exclusion criteria were smoking, trauma, or administration of drugs other than colchicine. This study was approved by the Research Ethics Committee of the NRC according to the World Association Declaration of Helsinki, and written informed consent was obtained from all patients' legal guardians.

Patients were subjected to detailed medical history, including demographic data, age at the onset, consanguinity, similarly affected family members with three-generation pedigree construction, meticulous clinical evaluation, and disease severity assessment using the scoring systems. ${ }^{15,16}$ The erythrocyte sedimentation rate, SAA, and CRP were assessed.

The blood samples from patients and controls were immediately centrifuged within 20 minutes at $3,000 \mathrm{~g}$ for 10 minutes and stored at $-20^{\circ} \mathrm{C}$ for subsequent assay. Serum S100A12 and resolvin D1 concentrations were evaluated using enzyme-linked immunosorbent assay kits (Human S100 Calcium Binding Protein A12, Human Resolvin D1, Bioneovan Co., Ltd; Beijing, China) according to the manufacturer's instructions.

\section{DNA Extraction}

All cases were diagnosed by molecular analysis of MEFV gene mutation. Genomic DNA was extracted from venous blood, according to Miller et al. ${ }^{17}$ Both MEFV exon 2 and $10^{18,19}$ were individually amplified by PCR using two pairs of primers: Exon 2: F: 5'- GCCTGAAGACTCCAGACCACCCCG-3', R: 5'- AGGCCCTCCGAGGCCTTCTCTCTG-3' Exon10: F: 5'GAGGTGGAGGTTGGAGACAA-3',R:5'-TGACCACCCACTGGACAGAT-3'

Bidirectional direct sequencing of purified PCR products was performed using the Big Dye Terminator V1.1 Cycle Sequencing kit (ABI prism, Foster City, California, United States) and an Applied Biosystems 3500DX Genetic analyzer.

Analysis of MEFV gene functional association and interaction with our biomarkers and their associated genes was performed using the Gene MANIA prediction server. ${ }^{20}$ The genes involved in the resolvin D1 biosynthesis pathway (Alox5) and S100A12 protein production were queried against the MEFV gene. Association links screening parameters included protein and genetic interactions, pathways, coexpression, and protein domain similarity.

Variation influence on the final protein structure and stability was modeled using Site-Directed Mutate webserver. ${ }^{21} \mathrm{~A}$ three-dimensional structure for wild-type protein was used as a reference with pdb id: 2WL1. Mutations M694I, V726A, A744S, and M680I were covered by the reference protein structure, and hence their influence was evaluated. 


\section{Statistical Analysis}

The variables were expressed as mean and standard deviation or as frequencies and percentage. Mann-Whitney U test was used for the comparison of the two groups. Spearman's correlation was used to assess the correlation between S100A12 and resolvin D and between S100A12, resolvin D, CRP, and serum amyloid $A$. In addition, it was used to analyze the correlation between the disease phenotypes and S100A12 and resolvin D biomarkers. The receiver operating characteristic (ROC) curve was used to evaluate the sensitivity and specificity of S100A12 and resolvin D1 to estimate the efficacy of these biomarkers in detecting the degree of inflammation. A significance level of $p<0.05$ was used in all tests. All statistical procedures were performed using SPSS version 20 for Windows (SPSS Inc, Chicago, Illinois, United States).

\section{Results}

The patients' mean age was $5 \pm 3.4$ years ( $3-13$ years); there were 32 males and 46 females with a M: F ratio of $1: 1.4$. Their mean disease duration was $4.56 \pm 2.21$ years. Consanguinity was present in $22(28 \%)$ cases. The number of attacks ranged from 2 to 3 times/week to 3 to 4 times/month. All patients were on colchicine treatment ranging from 0.5 to $3 \mathrm{mg} /$ day. Twelve patients (15.4\%) met the definition of refractory FMF.

The 60 controls were of matched age $5.96 \pm 2.25$ years (4-14 years) and gender (21 males and 39 female) (M: F $1: 1.8)(p=0.06$ and $p=0.47$, respectively).

The characteristics of the patients are presented in -Table 1. The mutational distribution is presented in -Table 2. This is a leading study on the link between the MEFV and relevant genes to the studied biomarkers to the best of our knowledge. The gene interaction network analysis using the GeneMANIA web tool showed that the MEFV gene possesses direct and indirect co-expression link evidence with genes responsible for producing biomarker S100A12, S100A8, and S100A9 (-Fig. 1).

- Table 3 showed the mutated protein structure stability. The available protein reference structure did not cover the residue location E148Q, while the remaining four mutations were subjected to the evaluation. The analysis revealed that three out of these four mutations resulted in increased structure stability (M694I, V726A, and M680I). Only A744S mutation caused reduced stability with a predicted $\Delta G$ difference from the wild type of negative 0.14 value. However, the M694I mutation, the most common mutation observed, caused increased residue solvent accessibility compared with the wild type and caused the loss of sidechain-sidechain hydrogen bond formation at the respective residue location suggesting marked structure conformational change at the mutation location. The mutation caused a positive increase in $\Delta \Delta \mathrm{G}$ by 0.72 , leading to a more stable structure than the wild type. M680I mutation shows the slightest difference in $\Delta \Delta \mathrm{G}$ in all studied mutations with only $0.03 \Delta \Delta \mathrm{G}$ change due to the variation with no marked protein structural property change.
Table 1 Characteristics of patients with FMF

\begin{tabular}{|c|c|c|}
\hline \multicolumn{2}{|c|}{$\begin{array}{l}\text { Variables } \\
\text { Mean } \pm \text { SD (range) or } n(\%)\end{array}$} & $\begin{array}{l}\text { FMF patients } \\
(n=78)\end{array}$ \\
\hline \multicolumn{2}{|l|}{ Age $(y)$} & $5 \pm 3.4(3-13)$ \\
\hline \multicolumn{2}{|c|}{ Gender (male/female) } & $32 / 46$ \\
\hline \multicolumn{2}{|c|}{ Disease duration (y) } & $4.56 \pm 2.21(5-10)$ \\
\hline \multicolumn{2}{|c|}{ Consanguinity } & $22(28)$ \\
\hline \multirow[t]{7}{*}{ Laboratory } & $\mathrm{ESR}(\mathrm{mm} / 1 \mathrm{st} \mathrm{h})$ & $29.5 \pm 24.9$ \\
\hline & Elevated ESR & $56(71.8)$ \\
\hline & CRP (mg/dL) & $22.2 \pm 17.2$ \\
\hline & Positive CRP & $50(64.1)$ \\
\hline & Anemia & $34(43.6)$ \\
\hline & Serum amyloid $\mathrm{A}$ & $70(89.7)$ \\
\hline & $\begin{array}{l}\text { Elevated liver function } \\
\text { tests }\end{array}$ & $4(5.1)$ \\
\hline \multicolumn{2}{|c|}{ Colchicine dose $(\mathrm{mg} / \mathrm{d})$} & $(0.5-3) 1.8 \pm 0.74$ \\
\hline \multirow[t]{3}{*}{ Echo } & $\begin{array}{l}\text { Patent foramen oval } \\
\text { and MVP }\end{array}$ & $4(5.1)$ \\
\hline & Mitral regurgitation & $4(5.1)$ \\
\hline & $\begin{array}{l}\text { Subcortical } \\
\text { epileptogenic activity }\end{array}$ & $1(1.3)$ \\
\hline \multirow[t]{4}{*}{ Abd. US } & $\begin{array}{l}\text { Mesenteric } \\
\text { lymphadenitis }\end{array}$ & $8(10.3)$ \\
\hline & $\begin{array}{l}\text { Epididymitis, } \\
\text { hydrocele and orchitis }\end{array}$ & $1(1.3)$ \\
\hline & $\begin{array}{l}\text { Lymphadenopathy, } \\
\text { splenomegaly, and } \\
\text { hernia }\end{array}$ & $1(1.3)$ \\
\hline & Fatty liver & $1(1.3)$ \\
\hline
\end{tabular}

Abbreviations: Abd. US, abdominal ultrasounds; CRP, C-reactive protein; Echo, echocardiogram; ESR, erythrocyte sedimentation rate; FMF, familial Mediterranean fever; MVP, major vault protein; SD, standard deviation.

Table 2 Mutational distribution among the FMF patients

\begin{tabular}{|l|l|}
\hline Gene mutations $\mathbf{n}(\%)$ & $\begin{array}{l}\text { FMF patients } \\
(\boldsymbol{n}=78)\end{array}$ \\
\hline MEFV & 78 \\
\hline Heterozygous & $60(76.9)$ \\
\hline M694I & $8(10.2)$ \\
\hline M6801 & $2(2.6)$ \\
\hline A744S & $2(2.6)$ \\
\hline E148Q & $2(2.6)$ \\
\hline V726A & $2(2.6)$ \\
\hline Homozygous & $2(2.6)$ \\
\hline E148Q &
\end{tabular}

Abbreviations: FMF, familial Mediterranean fever; MEFV, Mediterranean fever. 


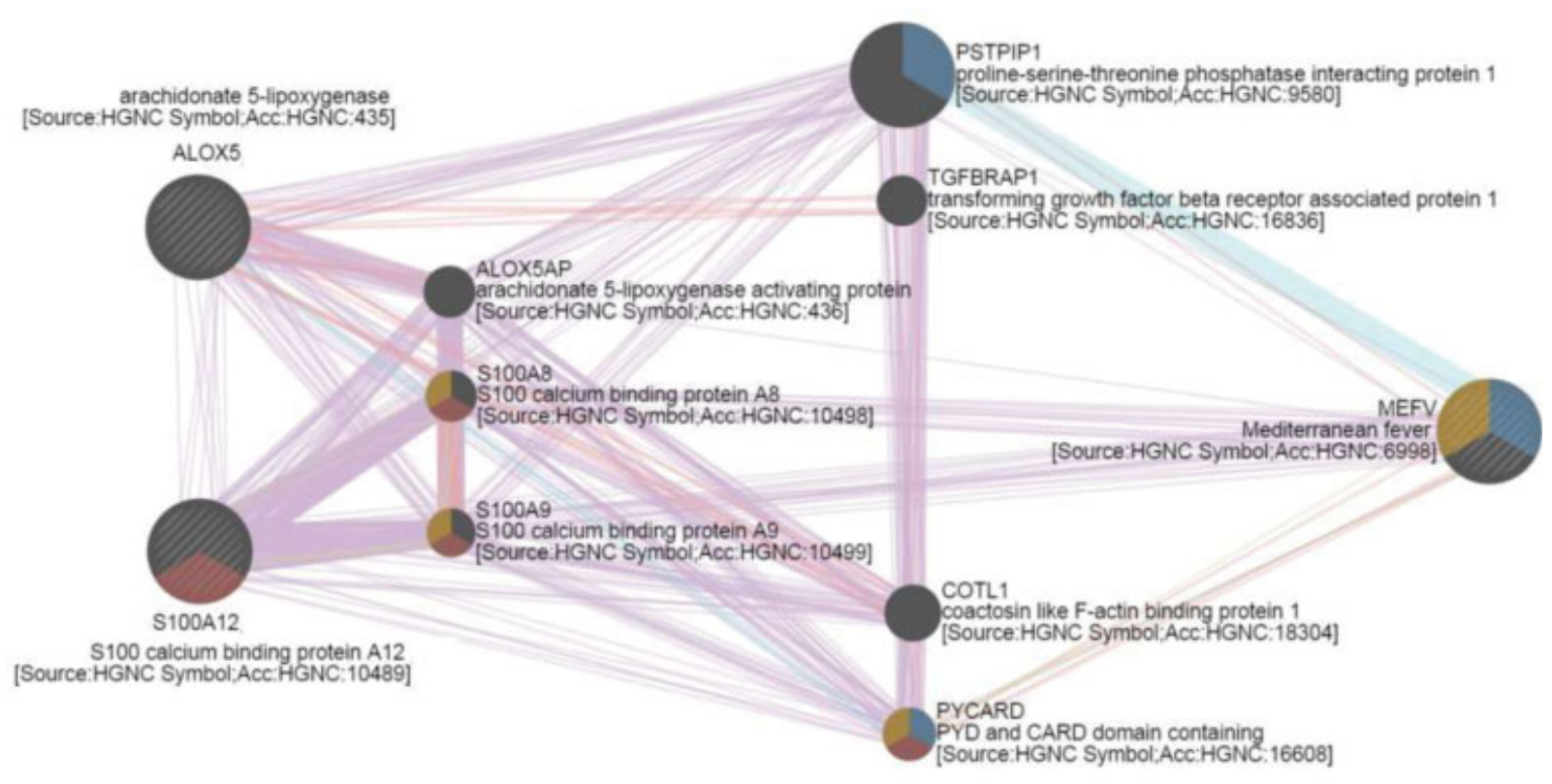

\section{Networks}

Physical Interactions Co-expression Pathway

Genetic Interactions

Shared protein domains

\section{Functions}

nucleotide-binding domain, leucine rich repeat containing receptor signaling pathway

positive regulation of NF-kappaB transcription factor activity

[1] positive regulation of cysteine-type endopeptidase activity

Fig. 1 Interaction network analysis among Mediterranean fever (MEFV) gene and genes associated with the production of S100A12 and resolvin D1. Interaction analysis showed a set of intermediate genes including (ALOX5AP, S100AB, S100A9, PYCARD, COTL1, PSTPIP1) sharing coexpression, protein-domain similarity and pathway interaction links connecting all MEFV, ALOX5, and S100A12 genes.

Table 3 Mutated protein structural stability analysis in FMF patients

\begin{tabular}{|c|c|c|c|c|c|c|c|c|c|}
\hline \multirow[t]{2}{*}{ Mutation } & \multicolumn{9}{|c|}{ Mutated protein structural stability analysis in FMF patients $(n=78)$} \\
\hline & Residue & RSA (\%) & Depth $(\AA)$ & OSP & SS & SN & SO & $\Delta \Delta \mathrm{G}$ & Stability \\
\hline \multirow[t]{2}{*}{ M694I } & Wild type & 40.3 & 4 & 0.32 & $\mathrm{~T}$ & $\mathrm{~F}$ & $\mathrm{~F}$ & \multirow[t]{2}{*}{0.72} & \multirow[t]{2}{*}{ Increased } \\
\hline & Mutation & 54.6 & 3.8 & 0.28 & $\mathrm{~F}$ & $\mathrm{~F}$ & $\mathrm{~F}$ & & \\
\hline \multirow[t]{2}{*}{ V726A } & Wild type & 56.3 & 3.5 & 0.21 & $\mathrm{~F}$ & $\mathrm{~F}$ & $\mathrm{~F}$ & \multirow[t]{2}{*}{0.12} & \multirow[t]{2}{*}{ Increased } \\
\hline & Mutation & 54.1 & 3.2 & 0.23 & $\mathrm{~F}$ & $\mathrm{~F}$ & $F$ & & \\
\hline \multirow[t]{2}{*}{ A744S } & Wild type & 67.9 & 3.2 & 0.24 & $\mathrm{~F}$ & $\mathrm{~F}$ & $\mathrm{~F}$ & \multirow[t]{2}{*}{-0.14} & \multirow[t]{2}{*}{ Reduced } \\
\hline & Mutation & 71.6 & 3.3 & 0.23 & $\mathrm{~F}$ & $\mathrm{~F}$ & $\mathrm{~F}$ & & \\
\hline \multirow[t]{2}{*}{ M680I } & Wild type & 52.7 & 3.7 & 0.17 & $\mathrm{~F}$ & $F$ & $F$ & \multirow[t]{2}{*}{0.03} & \multirow[t]{2}{*}{ Increased } \\
\hline & Mutation & 37.9 & 3.7 & 0.26 & $\mathrm{~F}$ & $F$ & $\mathrm{~F}$ & & \\
\hline
\end{tabular}

Abbreviations: F, false; FMF, familial Mediterranean fever; OSP, occluded surface packing; RSA, relative solvent accessibility; SN, sidechain-main chain amide hydrogen bond; SO, sidechain-main chain carbonyl hydrogen bond; SS, sidechain-sidechain hydrogen bond; SSE, main chain conformational class; T, true.

The serum levels of S100A12 and resolvin D1 were significantly increased in the FMF patients during colchicine treatment compared with the control (mean: $847.4 \pm 553$ $\mathrm{pg} / \mathrm{mL}$, median: 726.5 and $793.3 \pm 622 \mathrm{pg} / \mathrm{mL}, 700$ vs. $324.3 \pm 201.7 \mathrm{pg} / \mathrm{mL}$, median: 272.5 and $235.1 \pm 154.7$ $\mathrm{pg} / \mathrm{mL}, 261.5 ; p=0.001)$. Spearman's correlation test showed no significant correlation between S100A12 and resolvin D1 among cases with $\mathrm{rs}=0.014$ and $p=0.943$, although there was a highly significant correlation between S100A12 and resolvin D1 among controls with $\mathrm{rs}=0.627$ and $p=0.003$.

On comparing the serum levels between those with heterozygous mutation of M694I gene and those with other mutations, the levels were $842.4 \pm 611 \mathrm{pg} / \mathrm{mL}$, median 723.5 and $710.7 \pm 487.8 \mathrm{pg} / \mathrm{mL}, 572.5$ vs. $864 \pm 314.8 \mathrm{pg} / \mathrm{mL} 726.5$ and $958.4 \pm 841.9 \mathrm{pg} / \mathrm{mL}, 810 ; p=0.516$ and 0.607 (-Fig. 2). 


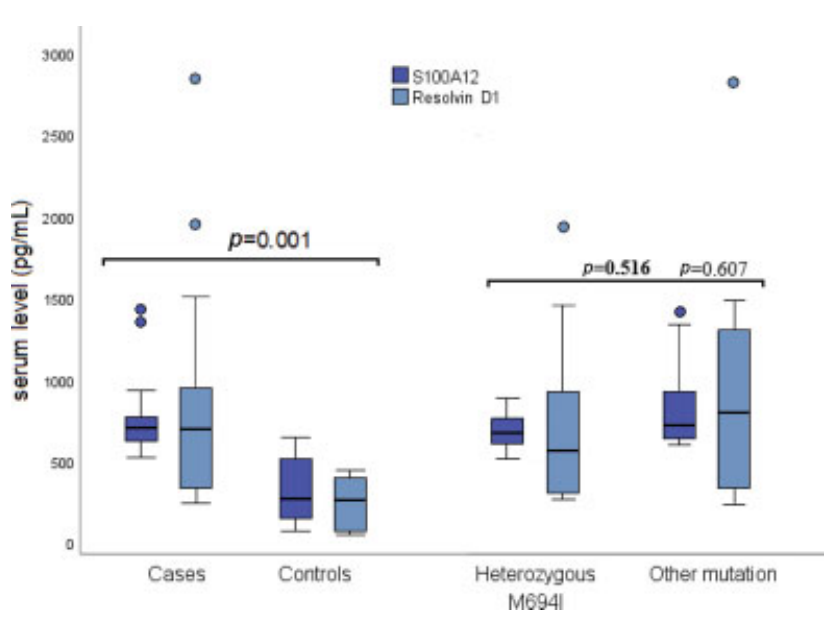

Fig. 2 Levels of S100A12 and resolvin D1 between familial Mediterranean fever patients and controls (left) and between those with M694I mutation versus other mutations (right).

Table 4 Spearman's correlation between S100A12 and resolvin $D$ versus serum amyloid $A$ and $C$-reactive protein

\begin{tabular}{|l|l|l|l|}
\hline S100A12 $(\mathrm{pg} / \mathrm{mL})$ & & $\begin{array}{l}\text { Serum } \\
\text { amyloid A }\end{array}$ & $\begin{array}{l}\text { C-reactive } \\
\text { protein }\end{array}$ \\
\hline \multirow{5}{*}{$\begin{array}{l}\text { Resolvin } \\
\mathrm{D}(\mathrm{pg} / \mathrm{mL})\end{array}$} & rs & $0.907^{\mathrm{a}}$ & $0.857^{\mathrm{a}}$ \\
\cline { 2 - 4 } & $p$-Value & 0.001 & 0.001 \\
\cline { 2 - 4 } & Significant & $\mathrm{HS}$ & $\mathrm{HS}$ \\
\cline { 2 - 4 } & rs & $0.983^{\mathrm{a}}$ & $0.925^{\mathrm{a}}$ \\
\cline { 2 - 4 } & S-Value & 0.001 & 0.0001 \\
\cline { 2 - 4 } & Significant & $\mathrm{HS}$ & $\mathrm{HS}$ \\
\hline
\end{tabular}

aspearman's rho.

The Spearman's correlations revealed a significant value with $p=0.001$ between the studied biomarkers and the classical inflammation markers (SAA and the C-reactive protein) (-Table 4 ) and between the disease phenotypes and both S100A12 and resolvin D1 biomarkers.

The sensitivity, specificity, and area under the curve (AUC) of S100A12 and resolvin D1 for the diagnosis of the inflammation degree in cases were $97.44 \%, 80 \%$, AUC 0.96 and $100 \%, 50 \%$, AUC 0.82, respectively, with $p=0.001$ ( - Fig. 3 ).
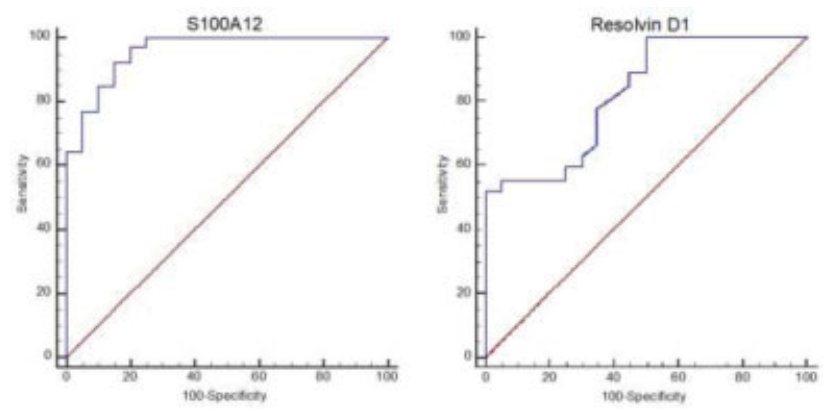

Fig. 3 The ROC curve of S100A12 and resolvin D1 was at a cutoff point of $529.5 \mathrm{pg} / \mathrm{mL}$ and $231 \mathrm{pg} / \mathrm{mL}$ respectively, their sensitivity was 97.4 and $100 \%$, specificity 80 and $50 \%$ respectively and the areas under the curve (AUC) was 0.958 and 0.82 respectively.

\section{Discussion}

FMF is the most common autoinflammatory disease prevalent in the Middle East. There is increasing demand for new biomarkers to estimate inflammation and treatment follow-up in FMF patients. In this study, the role of S100A12 and resolvin D1 was evaluated in the quiescent period to estimate the degree of inflammation. This may assist in further studies to adjust the doses of colchicine to ameliorate disease symptoms. The present study confirmed that the level of S100A12 was significantly increased in the quiescent period of FMF patients during colchicine treatment compared with controls. This coincides with previous studies. ${ }^{10,22,23}$ Therefore, S100A12 can be used to detect subclinical inflammation during the attack-free period.

According to the current study, the most common mutation was heterozygous M694I (76.9\%), heterozygous M680I (G/C) (10.2\%), followed by E148Q V726A, and A744S with lower frequencies. The M694V mutation could not be identified in this study in agreement with the results reported in previous work. ${ }^{18}$ Moreover, there was no significant difference in S100A12 levels between cases with heterozygous M694I mutation and those with other types of mutations. This may be due to the small number of FMF patients in the subgroups.

The current study showed S100A12 to be a reliable biomarker of inflammation during the quiescent period of FMF patients by the ROC test with high sensitivity, specificity, and highly significant $p$-value. Therefore, determining the level of S100A12 can help gauge the effectiveness of treatment by the detection of the degree of inflammation during the quiescent period of FMF. Resolvin regulates the proinflammatory state, and it actively promotes resolution via monocyte/macrophage uptake of debris and apoptotic polymorphonuclear neutrophils. ${ }^{23,24}$ Serhan $^{25}$ elucidated that resolvin was an important molecular player involved in the active termination of inflammation specialized proresolving mediators. When this active process fails, chronic inflammation may proceed to different disorders like rheumatoid arthritis, inflammatory bowel disease, and other autoimmune diseases. FMF is an autoinflammatory disease that primarily affects the leucocytes of the innate immune system. ${ }^{26,27}$ In the present study, the level of resolvin was significantly higher in the cases compared with the controls. This is in agreement with the study of Taylan et al. ${ }^{12}$ Additionally, no significant correlation was found in relation to the types of mutations.

The ROC curve enlightened that resolvin is a good diagnostic biomarker for the degree of inflammation in the quiescent period of FMF patients, besides its role in the resolution of inflammation and may point to the presence of subclinical inflammation.

The levels of S100A12 and resolvin D correlated significantly $(p<0.001)$ with the classical inflammatory biomarkers as $70(89.7 \%)$ patients had high serum amyloid levels, which agree with Lofty et al ${ }^{28}$ and Duzova et al. ${ }^{29}$ Similarly, Ben-Zvi and Livneh ${ }^{24}$ affirmed that although the 
patients are under treatment, both CRP and SAA increased in 30 to $90 \%$ of their patients during the episode-free period. On the other hand, Lachmann et $\mathrm{al}^{30}$ and Berkun et $\mathrm{al}^{31}$ reported elevated SAA during the attack-free periods in only 33.3 and $25 \%$ of their FMF patients, respectively. This could be due to the existence of subclinical inflammation in FMF patients.

In addition, CRP was elevated in 50 (64.1\%) cases higher than the findings of others studies. ${ }^{28,29,32}$ The number of patients with increased SAA was more than those with elevated CRP. This may be due to the high sensitivity of SAA in detecting the degree of inflammation. Furthermore, a correlation was detected between the clinical severity and S100A12 and resolvin D1 $(p<0.001)$. Similarly, Taylan et al ${ }^{12}$ delineated the role of S100A12 and resolvin D1 in revealing the clinical severity and the estimation of subclinical inflammation in FMF patients.

The bioinformatics analysis for the gene interaction network revealed a coexpression link between the MEFV gene and the genes responsible for the production of the two biomarkers of interest. The GeneMANIA web tool suggested a hidden functional association between the MEFV gene and both ALOX5 and S100A12. Moreover, the evaluation of those biomarkers' protein structure stability revealed that M694I, V726A, and M680I mutations resulted in an increase in their stability and helped improve the functions of the protein, contributing to the disease, while A744S mutation suppressed it.

This study's main limitation was that the control sample missed the presence of FMF patients with amyloidosis or Behcet disease.

In conclusion, S100A12 and resolvin D1 may be useful biomarkers in evaluating clinical severity and inflammation during the quiescent period of the disease in FMF patients. Further studies are needed to discover other biomarkers that might aid in diagnosing, following up, and treating FMF patients. Moreover, according to the bioinformatics analysis results, we recommend further study with a larger number of cases to determine if more genes possess coexpression link with the MEFV gene and the genes responsible for the production of the studied biomarkers and those affecting their structural stability.

\section{Funding}

None.

Conflict of Interest

None declared.

\section{References}

1 Guler T, Garip Y, Dortbas F, Dogan YP. Quality of life in Turkish patients with familial Mediterranean fever: association with fatigue, psychological status, disease severity and other clinical parameters. Egypt Rheumatol 2018;40:117-121

2 Salah S, Talaat HS, El Basha NR, Marzouk H, Abd Elhamid S, Shafie ES. Comparing D-dimer status in children with familial Mediterranean fever during and in between acute attacks. Egypt Rheumatol 2018;40:107-110
3 Ozen S, Batu ED, Demir S. Familial Mediterranean Fever: recent developments in pathogenesis and new recommendations for management. Review ARTICLE. Front Immunol 2017; $\cdots: 23$

4 Mohamed R, El-Bassyouni HT, Elwan SH, et al. Carotid intimamedia thickness, lipid profile, serum amyloid $A$ and vitamin $D$ status in children with familial Mediterranean fever. Egypt Rheumatol 2020;42:237-240

5 El-Shanti H, Majeed HA, El-Khateeb M. Familial Mediterranean fever in Arabs. Lancet 2006;367(9515):1016-1024

6 Aksentijevich I, Centola M, Deng Z, et al; The International FMF Consortium. Ancient missense mutations in a new member of the RoRet gene family are likely to cause familial Mediterranean fever. Cell 1997;90(04):797-807

7 Pietzsch J, Hoppmann S. Human S100A12: a novel key player in inflammation? Amino Acids 2009;36(03):381-389

8 Kallinich T, Wittkowski H, Keitzer R, Roth J, Foell D. Neutrophilderived S100A12 as novel biomarker of inflammation in familial Mediterranean fever. Ann Rheum Dis 2010;69(04):677-682

9 Kessel C, Holzinger D, Foell D. Phagocyte-derived S100 proteins in autoinflammation: putative role in pathogenesis and usefulness as biomarkers. Clin Immunol 2013;147(03):229-241

10 Serhan CN, Chiang N. Endogenous pro-resolving and anti-inflammatory lipid mediators: a new pharmacologic genus. Br J Pharmacol 2008;153(Suppl 1):S200-S215

11 Recchiuti A, Codagnone M, Pierdomenico AM, et al. Immunoresolving actions of oral resolvin D1 include selective regulation of the transcription machinery in resolution-phase mouse macrophages. FASEB J 2014;28(07):3090-3102

12 Taylan A, Gurler O, Toprak B, et al. S1000A12, Chitotriosidase, and resolvin D1 as potential biomarkers of familial Mediterranean fever. J Korean Med Sci 2015;30(09):1241-1245

13 Marzouka H, Mostafa N, Khalifa I, Badawi N. Effect of an increased dose of colchicine on microalbuminuria in children with familial Mediterranean Fever. Egypt Rheumatol 2020;42:141-145

14 Kisla Ekinci RM, Balci S, Dogruel D, Altintas DU, Yilmaz M. Canakinumab in children with familial Mediterranean fever: a singlecenter, retrospective analysis. Paediatr Drugs 2019;21(05):389-395

15 Pras E, Livneh A, Balow JE Jr, et al. Clinical differences between North African and Iraqi Jews with familial Mediterranean fever. Am J Med Genet 1998;75(02):216-219

16 Ozen S, Aktay N, Lainka E, Duzova A, Bakkaloglu A, Kallinich T. Disease severity in children and adolescents with familial Mediterranean fever: a comparative study to explore environmental effects on a monogenic disease. Ann Rheum Dis 2009;68(02):246-248

17 Miller SA, Dykes DD, Polesky HF. A simple salting out procedure for extracting DNA from human nucleated cells. Nucleic Acids Res 1988;16(03):1215

18 Zarouk WA, El-Bassyouni HT, Ramadan A, et al. Screening of the most common MEFV mutations in a large cohort of Egyptian patients with familial Mediterranean fever. Gen Rep. 2018;11:23-28

19 Mejtoute T, Sayel H, El-Akhal J, et al. The detection of a novel insertion mutation in exon 2 of the MEFV gene associated with familial Mediterranean fever in a Moroccan family. Hum Genome Var 2017;4:17023

20 Warde-Farley D, Donaldson SL, Comes O, et al. The GeneMANIA prediction server: biological network integration for gene prioritization and predicting gene function. Nucleic Acids Res 2010;38 (Web Server issue):W214-20

21 Pandurangan AP, Ochoa-Montaño B, Ascher DB, Blundell TL. SDM: a server for predicting effects of mutations on protein stability. Nucleic Acids Res 2017;45(W1):W229-W235

22 Wittkowski H, Frosch M, Wulffraat N, et al. S100A12 is a novel molecular marker differentiating systemic-onset juvenile idiopathic arthritis from other causes of fever of unknown origin. Arthritis Rheum 2008;58(12):3924-3931

23 Gohar F, Orak B, Kallinich T, et al. Correlation of secretory activity of neutrophils with genotype in patients with familial Mediterranean fever. Arthritis Rheumatol 2016;68(12):3010-3022 
24 Ben-Zvi I, Livneh A. Chronic inflammation in FMF: markers, risk factors, outcomes and therapy. Nat Rev Rheumatol 2011;7(02): 105-112

25 Serhan CN. Novel lipid mediators and resolution mechanisms in acute inflammation: to resolve or not? Am J Pathol 2010;177(04): 1576-1591

26 Ozen S, Uckan D, Baskin E, et al. Increased neutrophil apoptosis during attacks of familial Mediterranean fever. Clin Exp Rheumatol 2001;19(05, Suppl 24):S68-S71

27 Kholoussi S, Kholoussi N, Zaki ME, et al. Immunological evaluation in patients with familial Mediterranean fever. Open Access Maced J Med Sci 2018;6(02):310-313

28 Lofty HM, Marzouk H, Farag Y, et al. Serum amyloid A level in Egyptian children with familial Mediterranean fever. Int J Rheumatol 2016:7354018
29 Duzova A, Bakkaloglu A, Besbas N, et al. Role of A-SAA in monitoring subclinical inflammation and in colchicine dosage in familial Mediterranean fever. Clin Exp Rheumatol 2003;21(04): 509-514

30 Lachmann HJ, Sengül B, Yavuzşen TU, et al. Clinical and subclinical inflammation in patients with familial Mediterranean fever and in heterozygous carriers of MEFV mutations. Rheumatology (Oxford) 2006;45(06):746-750

31 Berkun Y, Padeh S, Reichman B, et al. A single testing of serum amyloid a levels as a tool for diagnosis and treatment dilemmas in familial Mediterranean fever. Semin Arthritis Rheum 2007;37 (03):182-188

32 Korkmaz C, Ozdogan H, Kasapçopur O, Yazici H. Acute phase response in familial Mediterranean fever. Ann Rheum Dis 2002;61 (01):79-81 